
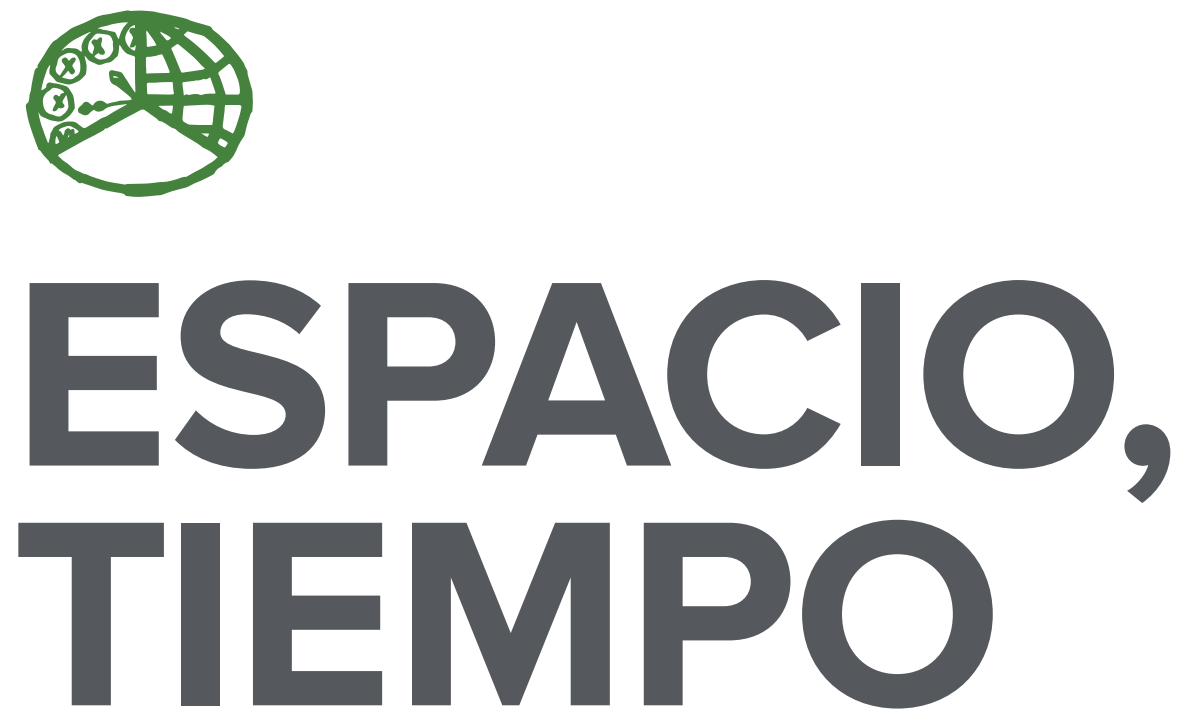

AÑO 2018 ISSN

$1130-2968$

E-ISSN 2340-146X
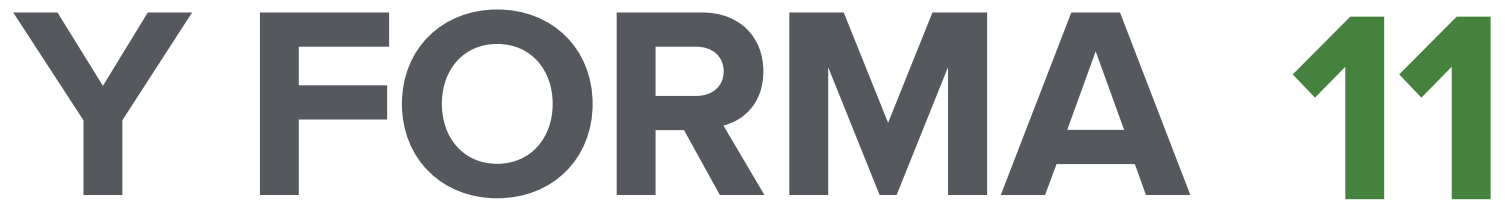

SERIE VI GEOGRAFÍA

REVISTA DE LA FACULTAD DE GEOGRAFÍA E HISTORIA 


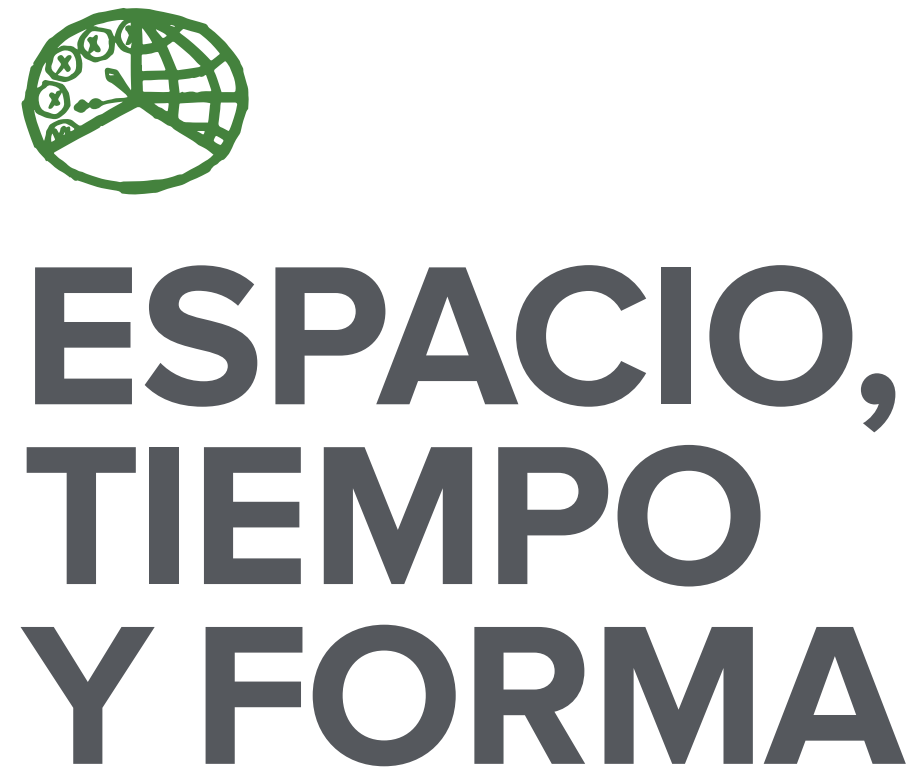

AÑO 2018

ISSN 1130-2968

E-ISSN 2340-146X

SERIE VI GEOGRAFÍA

REVISTA DE LA FACULTAD DE GEOGRAFÍA E HISTORIA

DOI: http://dx.doi.org/10.5944/etfvi.11.2018

\section{UกED}

UNIVERSIDAD NACIONAL DE EDUCACIÓN A DISTANCIA 
La revista Espacio, Tiempo y Forma (siglas recomendadas: ETF), de la Facultad de Geografía e Historia de la UNED, que inició su publicación el año 1988, está organizada de la siguiente forma:

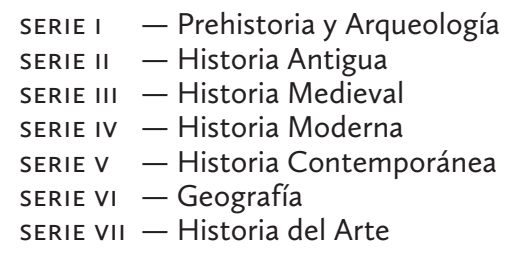

Excepcionalmente, algunos volúmenes del año 1988 atienden a la siguiente numeración:

$$
\begin{aligned}
& \mathrm{N}^{\circ} 1 \text { - Historia Contemporánea } \\
& \mathrm{N}^{\circ} 2 \text { - Historia del Arte } \\
& \mathrm{N}^{\circ} 3 \text { - Geografía } \\
& \mathrm{N} .^{\circ} 4 \text { - Historia Moderna }
\end{aligned}
$$

ETF no se solidariza necesariamente con las opiniones expresadas por los autores.

\author{
UNIVERSIDAD NACIONAL DE EDUCACIÓN A DISTANCIA \\ Madrid, 2018 \\ SERIE VI $\cdot$ GEOGRAFÍA N. ${ }^{\circ} 11,2018$ \\ ISSN 1130-2968 - E-ISSN 2340-146x \\ DEPÓSITO LEGAL \\ $M-21.037-1988$ \\ URL \\ ETF VI - GEOGRAFÍA $\cdot$ http://revistas.uned.es/index.php/ETFVI \\ DISEÑO Y COMPOSICIÓN \\ Carmen Chincoa Gallardo · http://www.laurisilva.net/cch \\ Impreso en España · Printed in Spain
}




\section{HISTORIA DE LA GEOGRAFÍA ESPAÑOLA}

- HISTORY OF GEOGRAPHY IN SPAIN 



\title{
TERCERA ENTREGA
}

\author{
NOTA PRELIMINAR
}

El descubrimiento de América y la creación del imperio español abren una nueva realidad para la humanidad, poniendo las bases de un proceso imparable de conexión entre los diferentes continentes que es el germen de la actual globalización. A partir de este momento todo cambió; las fuentes del poder, que ya no se limitan al Viejo Mundo; el conocimiento de la naturaleza, que se abre a nuevas especies vegetales y animales; las posibilidades del comercio, que revolucionan la economía a favor del sector terciario; en fin, la mente humana que se abre a una dimensión renovada. En este panorama no podía permanecer inmutable la Geografía que se desbordaba por el «aumento del mundo» y por el incremento de los contactos más o menos traumáticos de las culturas humanas. Aún está por hacer la historia de las aportaciones de los geógrafos hispanos de un lado y otro del Atlántico entre el siglo XVI y el XIX.

A finales del siglo XVIII, el viaje de Alejandro de Humboldt al Nuevo Mundo va a suponer un avance espectacular para la Geografía, ya que se reconsideran a la luz de nuevos planteamientos las tierras americanas. Normalmente esta aventura intelectual, que a todos nos fascina y siempre llenará páginas de nuestra disciplina, ha sido narrada desde posiciones hagiográficas y poco favorables a señalar los aspectos discutibles (que los hay). Esta pequeña aportación pretende contextualizar y aclarar un momento poco conocido de la historia de la ciencia dieciochesca: el encuentro de Humboldt en tierras mexicanas con Andrés Manuel del Río. Sirve también para reflexionar sobre la Geografía en el contexto del enciclopedismo tardío, una época en la que los científicos aún no definían sus disciplinas de manera exclusivista como sí va a suceder en las siguientes generaciones y hasta la actualidad. 


\title{
ALEJANDRO DE HUMBOLDT Y ANDRÉS MANUEL DEL RÍO. ENCUENTROS Y DESENCUENTROS EN LA CIENCIA DE LA NUEVA ESPAÑA
}

\author{
ALEXANDER VON HUMBOLDT AND \\ ANDRÉS MANUEL DEL RÍO. AGREEMENTS \\ AND DISAGREEMENTS ON NUEVA \\ ESPAÑA REGION'S SCIENCE
}

\author{
Aurelio Nieto Codina ${ }^{1}$ \\ Recibido: 11/05/2018 - Aceptado: 11/07/2018 \\ DOI: http://dx.doi.org/10.5944/etfvi.11.2018.22342
}

Lo que entendemos hoy por geografía no se corresponde con lo que pensaban los naturalistas que trabajaban a finales del siglo XVIIl y comienzos del XIX, ya que en aquella época la geografía se relacionaba más con las ciencias narturales que con las ciencias sociales. En las postrimerías de la llustración, el estudio de la naturaleza se encontraba en un momento de cambio, ya que se estaba produciendo la paulatina definición, consolidación e implantación de la teoría del evolucionismo. Al mismo tiempo, las disciplinas científicas se preparaban para el gran acontecimiento que supondría en el siglo XIX la nueva institucionalización académica en el seno de las universidades. En este contexto, la geografía tenía la fortaleza, o mejor el amparo, de una amplia tradición que nacía en la antigüedad clásica, al mismo tiempo estaba sufriendo la amenaza de una imparable desmembración en lo que a los contenidos respecta. En efecto, no se puede ocultar que el proceso de especialización académica que se inauguraba en este momento, y que llega hasta nuestros días, no encajaba demasiado bien en una disciplina científica que trataba de conjugar entre sus intereses tanto el estudio de lo referente al medio físico como los avatares de las actividades humanas.

En la transición entre los siglos XVIII y XIX, en los territorios de la América española y sobre todo en lo que entonces se conocía como Nueva España, se estaban produciendo una serie de prácticas científicas en el campo de la minería y de la botánica que iban a marcar el desarrollo de la Geografía. Personificamos esta afirmación en dos científicos destacados. En primer lugar, uno de los científicos más famosos de la época, y podemos decir de todos los tiempos, Alejandro de Humboldt, había conseguido que las autoridades españolas desde Madrid le dieran

1. Profesor asociado. Departamento de Geografía de la Universidad Nacional de Educación a Distancia; <ancodina@geo.uned.es>. 
vía libre para recorrer a su antojo el Nuevo Continente, además se le permitía consultar los archivos que estimase oportuno y recabar la ayuda del personal ligado administrativamente a la autoridad de la corona. El citado barón prusiano, que simbolizaba en su época los adelantos de la ciencia ilustrada, es visto hoy día como uno de los fundadores de la Geografía moderna². Según mi criterio, más que como el padre de una determinada disciplina científica, creo que hay que enfrentarse a Humboldt como un investigador (en ocasiones un ensayista) que amalgama en su obra un pensamiento misceláneo que gira en torno al concepto de Naturaleza (lo que hoy se llama medioambiente). También hay que considerarlo como un muy productivo escritor, poseedor de una enorme capacidad de trabajo y capaz de sintetizar datos e ideas de muy diversa procedencia. A lo largo de sus trabajos publicados, Humboldt nos arrastra con su capacidad de seducción y encuentra un terreno fértil sobre todo cuando se dedica a la descripción de paisajes; ; al mismo tiempo, en ningún momento oculta su enorme autoestima y una capacidad indiscutible para hacer propaganda de si mismo. Ambas estratégias son básicas para difundir cualquier trabajo creativo y válidas tanto ayer como hoy.

El reconocimiento de Humboldt como enciclopedista, recopilador y analista de diferentes saberes es un asunto, y que los geógrafos reconozcan su trabajo como un modelo a seguir en sus investigaciones, otro. Aunque en teoría se dice admirar su trabajo, en la práctica, cuando se desarrolle en el siglo XIX la Geografía en su variante conocida como Geografía física, esta va a seguir unos caminos que no coinciden con los humboldtianos. No se ha insistido lo suficiente en señalar que los avances metodológicos y de contenidos que la Geografía física desarrolla en medios académicos decimonónicos se inscriben en las parcelas de la edafología y la climatología, dos disciplinas que nacen en Rusia al margen del magisterio de Humboldt ${ }^{4}$.

Nuestro segundo personaje reseñado es menos conocido: Andrés Manuel del Río. Al margen de biografías más o menos laudatorias, es realmente difícil acceder a una historia de la ciencia que nos presente la trayectoria vital y profesional del geólogo-geógrafo novohispano5. A. M. del Río y Fausto Elhúyar inauguran en 1792 el Real Seminario de Minería de la Nueva España, creado por real decreto de Carlos III, reservándose para el primero la cátedra de Química y Mineralogía. Se escribe aquí uno de los capítulos más importantes de la historia de la minería como disciplina práctica y teórica a nivel mundial, es evidente que se trata de un tema que

\footnotetext{
2. En este sentido se manifiesta Horacio Capel, que lo reconoce como «padre putativo» de la Geografía. Véase al respecto el capítulo primero de Capel (1981).

3. En sus Cuadros de la Naturaleza, Humboldt trata de acercarse al estudio de los paisajes presentando datos recopilados en sus viajes y desplegando una capacidad literaria que no desdeña incorporar lo que podríamos llamas «aspectos estéticos». Humboldt (2003).

4. Frolova (2002). La investigadora Marina Frolova destaca la importancia de Vasili Dokucháyev como fundador de la edafología, un gran estudioso de los suelos chernozem, muy abundantes en Rusia. Otro de los grandes de la geografía rusa de esta época fue Wladimir Peter Köppen, sobradamente conocido por su clasificación climática y por ser pionero en el estudio de la paleogeografía climática. Aunque normalmente se considera a Köppen alemán, tanto por su ascendencia y como por haber desarrollado allí su trabajo principal, no se puede olvidar que nació en Rusia y que allí se formó académicamente, además también trabajó en el servicio imperial ruso de meteorología.

5. Una excepción sería la obra de FORTES, J.; ADLER, L. (1990), una historia circunscrita al ámbito mejicano. Exiten referencias en artículos concretos de investigacion en relacion con sus descubrimientos químico-mineralógicos.
} 


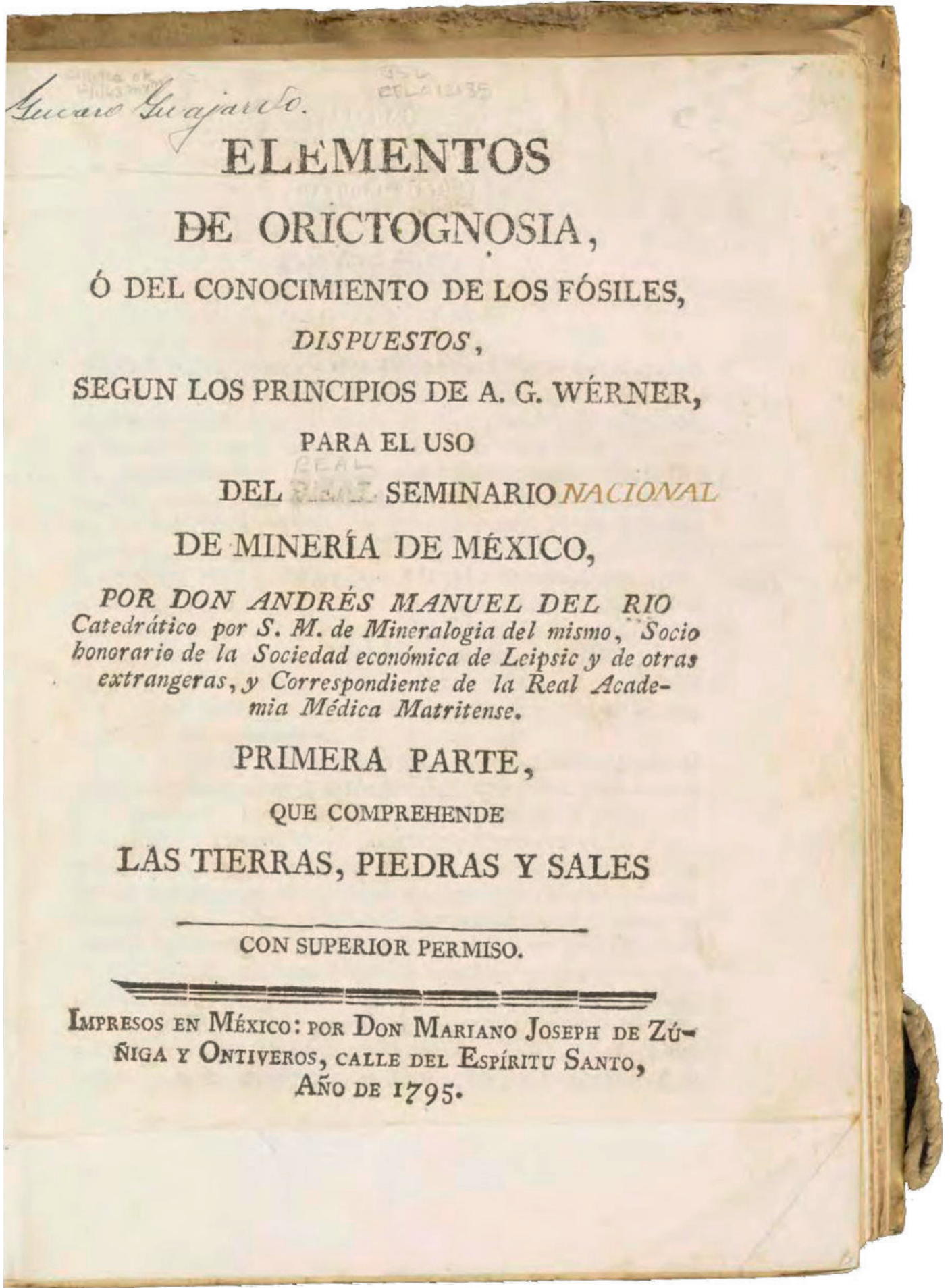

FIGURA 1. PORTADA DE ELEMENTOS DE ORICTOGNOSIA, PROCEDE DEL EJEMPLAR CONSERVADO EN THE AMERICAN MUSEUM OF NATURAL HISTORY (NUEVA YORK).

Véase como se ha tachado de Real Seminario de Minería de México la palabra «Real» y se ha sustituido por «Nacional». De este modo, los nacionalistas independentistas se apropian simbólicamente de una obra publicada en 1795, cuando aún México no era un estado independiente. 
merecería un trabajo en profundidad que está por realizar. Al mismo tiempo, en México se producía una actuación pionera en lo que al estudio académico de las ciencias de la Tierra se refiere: se creaban nuevas cátedras en el nivel superior de la educación. Este asunto tampoco está muy estudiado y no se profundiza en él, no hay que ser malpensado pero pareciera que se teme descubrir que a este nivel los avances novohispanos eran superiores a las realizaciones europeas, por supuesto no se encuentra nada igual en Norteamérica que en aquel momento tenía un sistema universitario poco desarrollado. Así, no es extraño que cuando Humboldt arriba a México, se sorprenda al conocer a A. M. del Río y al Real Seminario. Rápidamente los dos naturalista se reconocen como colegas y entablan una amistad que se afianza cuando comparten excursiones por el centro de México a Chapultepec, a las zonas basálticas de Xitle y al Peñón de los Baños, recogiendo ejemplares y muestras minerales para realizar posteriores análisis geológicos y químicos. A. M. del Río era sin duda el experto en minerales ya que en 1795 había escrito una obra fundamental: Elementos de Orictognosia ${ }^{6}$. Este es un manual que era utilizado por los alumnos del Real Seminario (Figura I), en sus páginas el autor demuestra que estaba al tanto de las novedades desarrolladas por la geología europea, asimilándolas y ampliándolas, se relaciona por tanto con los postulados de A. G. Werner, primer geólogo que sigue una metodología rigurosa, en la que prima la sencillez y la utilización de criterios referidos a la composición química de los minerales. En algunos inventarios y catálogos posteriores al libro de del Río aunque no muy lejanos en el tiempo, se seguían catalogando los minerales según los principios de la alquimia. Por ejemplo, en la expedición realizada por los hermanos Heuland y patrocinada por Carlos IV a Chile y Perú (I795-I800) que en lo que al uso de la simbología respecta tienen que ver más con la magia que con la ciencia, los grupos minerales se clasifican como en un tratado de astrología poniendo en relación rocas y planetas. Del Río es mucho más preciso en su clasificación y no olvida contextualizar su inventario mineralógico según principios geográficos de localización, insiste en señalar yacimientos, canteras y minas para poder dar una ubicación real a los ejemplos de los diferentes minerales reseñados en su libro. El esquema se repite a lo largo de toda la obra; se clasifica, describe y cataloga cada mineral y se localizan zonas en que se puede recolectar. Curiosamente Humboldt había sido discípulo de Werner y estaba al día de las novedades geológicas, en este sentido valoró positivamente la obra de del Río. Y es que los Elementos de Orictognosia tienen unos planteamientos metodológicos que siguen siendo válidos, y aunque como no podía ser de otro modo se ha avanzado mucho en la mejora de las técnicas de análisis y en la definición físico-química de los minerales, lo cierto es que la lectura del manual novohispano no chirría al lector actual. Es sorprendente que cuando años después del Río estuvo exiliado en Estados Unidos

6. Elementos de Orictognosis tiene el siguiente subtítulo «del conocimiento de los fósiles, dispuestos, según los principios de A. G. Werner, para el uso del Real Seminario de Minería de México». Si se consulta el libro I resulta que el estudio de los fósiles se deja para mejor ocasión y se centra sobre todo en clasificar los minerales desde principios racionales y sistemáticos desconocidos en su época.

7. Martín Vaqueiro (2017), pág. 173. 
por discrepancia con los primeros gobiernos del México independiente, se realizase en Filadelfia una reedición de su libro (1835), con lo cual se confirma el interés de los norteamericanos yanquis por las aportaciones científicas de del Río. Punto de partida para el desarrollo de las ciencias de la Tierra en territorio estadounidense.

Llegados a este punto, conviene insistir sobre la presencia o ausencia de planteamientos realmente geográficos en la obra de estos dos naturalistas contemporáneos que estamos comparando. En el caso del novohispano, del Río, no se pretende presentarlo como otro «antepasado» de los modernos geógrafos, sería un error definir un personaje del pasado según los deseos del presente, pero sí que hay que tener claro que fue lo suficientemente inteligente como para no excluir de su obra mineralógica los parámetros geográficos. Por otro lado, en la obra de Humboldt las referencias geográficas aparecen inmersas en el océano de las ciencias naturales, tal vez la única obra en la que se define plenamente como geógrafo sea su trabajo sobre fitogeografía de i805: Essai sur la géographie des plantes. Aquí se concretan los diferentes pisos vegetales determinados por la altitud, recalcando la importancia de la localización topográfica, en el resto de su obra no es fácil encontrar explicaciones geográficos individualizadas y tan bien delimitadas. La opción explicativa humboldtiana suele ser multidisciplinar típica de los investigadores enciclopedistas, así, por ejemplo, cuando estudia los sistemas montañosos insiste en acudir «tanto al punto de vista de la geografía y de la astronomía, como bajo el de la hispsometría, de la geognosia o de la botánica»8.

La extraordinaria expedición de Humboldt que comienza en Madrid y las Islas Canarias para continuar por los territorios americanos (visitando los actuales Colombia, Venezuela, México, Cuba, Estados Unidos, etc.) no hubiera sido posible sin la plena colaboración de las autoridades españolas. En este sentido, el científico prusiano siempre estuvo agradecido a los gobernantes y a todas las personalidades que le apoyaron en su aventura, tanto en la metrópoli como en las provincias americanas. La generosidad de las personas con las que contacto se manifiesta en la falta de obstáculos a sus movimientos, en la entrega de ejemplares recolectados y en el acceso a toda la información estadística demanda por él. Al mismo tiempo, Humboldt corresponde entregando muestras recolectadas por el mismo e informes científicos que considera de interés para los españoles. Así lo expresa en el siguiente fragmento:

«Durante mi permanencia en América entregué a los gobernadores de las provincias copias del material que iba recogiendo sobre la geografía y estadística de las colonias, que pudiera tener algun valor para la metrópoli. Cumpliendo con mi promesa, formulada antes de mi partida, envié varias colecciones geológicas al Gabinete de Historia Natural de Madrid (Figura 2). Como la finalidad de nuestro viaje era exclusivamente científico, Bonpland y yo tuvimos la suerte de ganarnos la benevolencia tanto de los colonos como de los europeos a cuyo cargo estaba el gobierno y la administración de aquellas dilatadas tierras. En los cinco años que invertimos recorriendo el Nuevo Continente, nunca observamos el menor síntoma de desconfianza. En medio

8. Humboldt (2003), pág. 172. 
de las privaciones más duras, en lucha con una naturaleza salvaje, jamás tuvimos que quejarnos de una injusticia humana»?.

Humboldt permanece en la ciudad de Méjico desde marzo de I803 hasta marzo de I804, en esta estancia visita y entra en contacto prolongado con la ya mencionada Real Escuela de Minas, dando conferencias, participando en examenes orales e incluso vendiendo instrumental científico traído por él de Europa. Al mismo tiempo y aproximadamente durante seis meses recorre el distrito minero del centro de Méjico entorno a la antigua capital azteca, estudiando la tecnología minera del momento y los métodos de procesamiento del mineral extraído de las minas. Todos los datos recopilados en este momento sobre producción minera, recursos económicos y demografía de las tierras mexicanas los utilizó en la redacción de su Ensayo Político de la Nueva España ${ }^{10}$. Generalmente no se incide en que la búsqueda de información e incluso su misma elaboración coinciden con la intensa amistad de Humboldt y del Río, que había nacido en un periodo anterior. Humboldt se refiere a su amigo como «un distinguido químico» y redacta para el tomo segundo de una reedición de los Elementos de Orictognosia un prefacio titulado Introducción a la Pasigrafía Geológica. Nos interesa esta amistad no por curiosidad biográfica sino porque fue realmente productiva en el aspecto científico para ambos.

El Ensayo Político de Humboldt destaca por ofrecer una amplia selección de datos demográficos y económicos, al tiempo que se presentan al lector de una manera atractiva; sin embargo, al sacar conclusiones o dar explicaciones razonados de esos datos Humboldt se apoya en unos fundamentos teóricos que ya estaban superados en el momento de la publicación del ensayo. En efecto, el esquema teórico de referencia es la fisiocracia, una doctrina económica que pone el acento explicativo en la importancia de la agricultura como base del desarrollo y el progreso. Sirva de ejemplo el siguiente párrafo, en el que se insiste en la importancia del sector primario como único motor de la economía mexicana:

«Acabamos de examinar (...) la verdadera riqueza nacional del reino de Méjico; pues, los produc-
tos de la tierra son realmente la única basa de una opulencia duradera (...) En efecto, consuela
ver que los afanes del hombre, de cincuenta años á esta parte, mas se han dirigido hácia este
manantial fecundo é inagotable, que hácia el beneficio de las minas, cuyas riquezas no influyen,
directamente en la pública, ni cambia mas que el valor nominal del producto anual de la tierra» ${ }^{11}$.

Humboldt compara la recaudación del diezmo que grava la agricultura con la produccion minera, así, la producción agrícola supone un ingreso de «29 millones de pesos anuales según calculo de diezmos que reduciéndolos á una media natural, y tomando por basa el precio actual del trigo en el reino de Méjico, que es á tres pesos por diez miriagramas, equivale a 96 millones de miriagramas de trigo. La masa de metales

9. HumbOLDT (1997), pág. 17.

10. Para una mayor información sobre la relación entre los dos naturalistas se debe consultar; CASWELL (2003).

11. HumbOLDT (1827), pág. 441. 


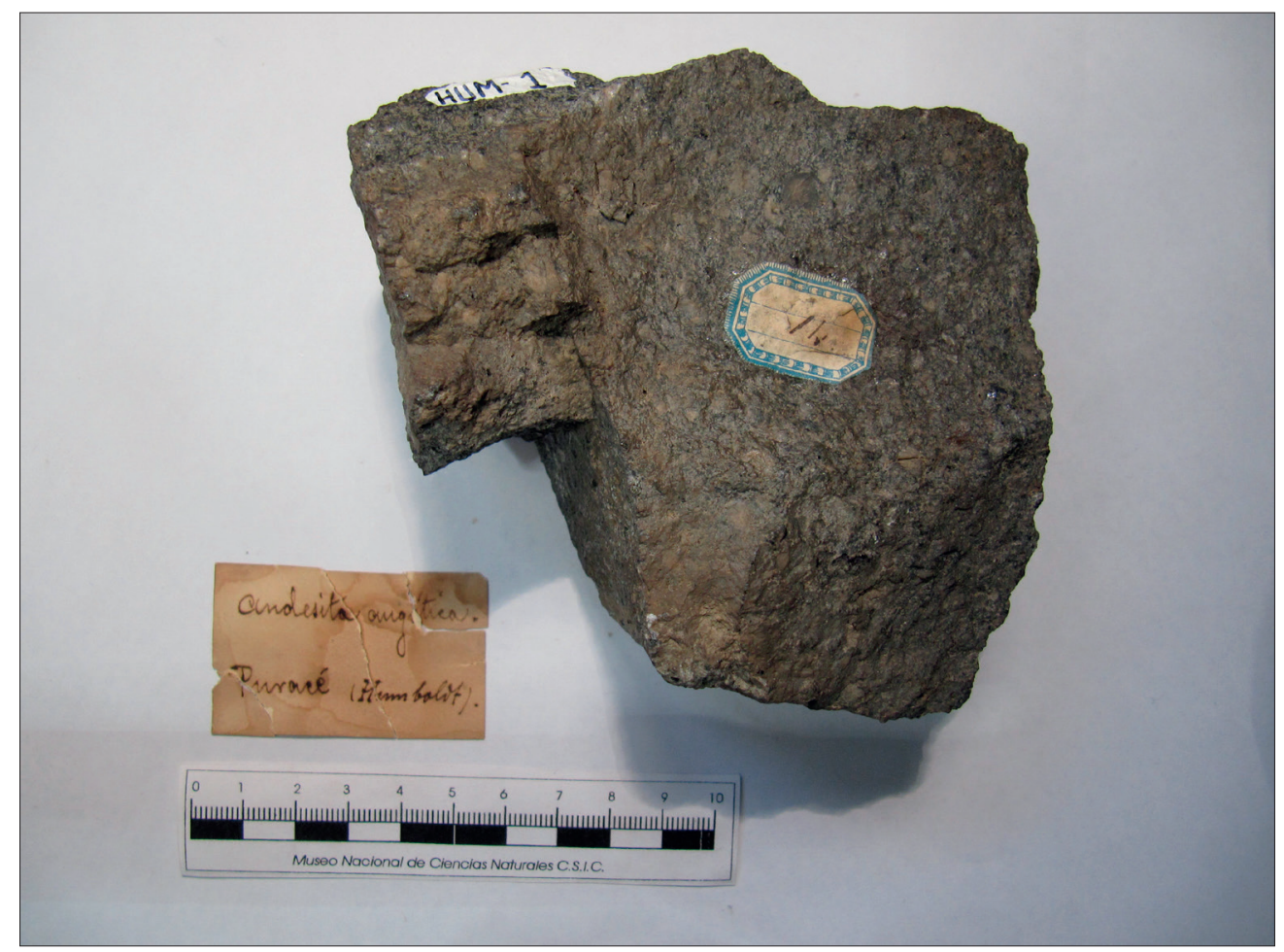

FIGURA 2. ANDESITA DE PURACÉ (COLOMBIA).

Ejemplar recolectado por Humboldt y conservada en el Museo Nacional de Ciencias Naturales de Madrid con el $n^{\circ}$ inventario 18170. Un ejemplo de la consideración del naturalista hacia una institución científica española a la que remitió parte de sus colecciones minerales.

preciosos, beneficiada anualmente en la Nueva España, apenas representa 74 millones de miriagramas de trigo ${ }^{12}$.

Esta fisiocracía tardía llama la atención en una época en la que Adam Smith y David Ricardo ya habían publicado las obras inaugurales del liberalismo económico que dejaban obsoletos los principios fisiocráticos. Más interesantes son las reflexiones de Humboldt en el capítulo XI del Ensayo (libro IV). En relación con la búsqueda del platino en tierras americanas, un asunto capital para la historia de la minería española, se reflexiona otras cosas sobre la importancia de disponer de colecciones mineralógicas para favorecer las investigaciones de los estudiantes de la Real Escuela, no dudando en criticar las colecciones minerales que solo se preocupan de las grandes piezas vistosas y no colectan ejemplares en el medio local, un problema detectado tanto en México como en Madrid. A Humboldt le interesa más el desarrollo de los aspectos didácticos que los criterios museísticos expositivos de tipo vistoso. Siguiendo con sus comentarios mineralógicos, resalta la importancia de las minas de plata de Guanajuato, en concreto menciona la mina de La Valenciana, lugar clave de la región. También hace mención a la forma de explotación de las minas, constata que no existe trabajo forzado, ni esclavos. Incluso insiste en afirmar que el minero mejicano es el mejor pagado de los mineros que él conoce.

12. Humboldt (1827), pág. 443. 
Además reconoce su admiración por los avances en la amalgama de la plata, es por tanto un difusor de los aspectos positivos de la minería novohispana, tanto en lo que supone la divulgación de las minas más destacadas de la región como en la defensa de unas condiciones de trabajo dignas para los mineros. En fin, podríamos alargarnos en multitud de aspectos relacionados con el Ensayo, solo reseñar que Humboldt es un autor que en esta obra toma conciencia de cómo el contexto histórico repercute de manera directa en la economía, fue un testigo privilegiado de la incidencia que las conmociones políticas vividas en aquel momento en América tuvieron en la economía, y demostró que la producción minera retrocede entre i8io y I8I7 (periodo de la revueltas e independencia), en comparación con el periodo comprendido entre I492 y I803, que es de claro auge o al menos de estabilidad, no detectando periodos a la baja con anterioridad a i8io.

Todo el material recopilado por Humbodt para realizar su ensayo y las obras posteriores referidas al Nuevo Mundo formaban un fondo documental del que se hicieron varias copias, una de ellas la utilizaría el propio autor para sus publicaciones, otra se puso al servicio de las autoridades novohispanas (luego en poder de los republicanos mexicanos) y una tercera copia pasó a los vecinos del norte, estaba formada por un conjunto de «mapas y documentos que fueron un instrumento formidable en los planes imperialistas de los estadounidenses, y hasta mediados de siglo tuvieron consideración de documentos de Estado. Los estudiantes de minería y otros estudiantes novohispanos que ayudaron a Humboldt llevados de un loable celo ilustrado, no supieron realmente para quién trabajaban $»^{13}$. Paradojas del mundo académico, en algunas ocasiones la documentación científica recopilada por un investigador no tiene solamente el objetivo de favorecer el avance de la ciencia, también se puede poner al servicio de objetivos políticos.

La buena relación de los dos naturalistas que se traduce en una fructífera producción científica ya mencionada se convierte en desencuentro cuando Humboldt abandona América y regresa a Europa. Más allá de la anécdota, el hecho es trascendente por sus consecuencia para la historia del ciencia. A. M. del Río había descubierto entre las muestras recogidas en las minas del centro de México un nuevo elemento químico: el vanadio, pero para que se produjera un reconocimiento internacional de este descubrimiento se necesitaba la aprobacion de los medios científicos europeos. El nuevo elemento era parte de un nuevo mineral descubierto en Zimapán, en lo que hoy es el estado mexicano de Hidalgo, se trata de la Vanadinita ${ }^{\text {I4 }}$. En aquella época a falta del nombre actual se conocía como "plomo pardo», y del Río entregó a Humbdodt una caja con muestras de este mineral y de otros varios para repetir en Europa los análisis que él ya habia realizado en México, los resultados también habían sido publicados pero en medios americanos que no tenían prestigio en Europa. Humboldt, que desconocía el procedimiento de análisis químico de los minerales, entrega las muestras a Hyppolite Victor Collet-Descotils para que

13. Roca Barea (2017), pág. 350

14. En la base de datos minerales on line de Mindat se reconoce a del Río como descubridor del vanadio y de la vanadinita. <https://www.mindat.org/min-4139.htm/>. 
repita el proceso realizado por su colega, pero el químico francés dice que el «análisis del plomo pardo de la mina de Zimapán, en el reino de Méjico, enviado por Humboldt y dado a aquel por Manuel Del Río, y que dice haber descubierto un nuevo metal» no lo es, ya que según él se trata de un mineral ya conocido formado por cromo, no por vanadio ${ }^{15}$. Humboldt se mueve aquí en un terreno científico que no controla y debía por tanto poner su credibilidad o bien en el español o bien en el francés, decidió finalmente que la balanza se debía inclinar sobre el segundo traicionando a su colega americano. A. del Río, decepcionado por la falta de apoyo de su amigo le escribe una carta en términos recriminatorios y en referencia a los análisis del «plomo marrón», cuestión clave para determinar el descubrimiento del nuevo elemento químico le dice a su amigo alemán:

«consideras oportuno dar la muestra mineral a tu amigo (alemán) ${ }^{16}$, sin duda por la razón de pensar que los españoles no deberíamos hacer ningún descubrimiento, no importa cuán pequeño sea, ya sea en química o mineralogía, siendo este un monopolio de los extranjeros».

La decepción por no ser reconocido su descubrimiento le lleva a la ironía haciéndose una pregunta retórica: «iHe perdido credibilidad por no conocer las propiedades del cromo en un país tan carente de libros y donde por la misma razón las ciencias son tan poco cultivadas?». Termina la misiva recriminando a su antiguo amigo y colega:

«Creo que en compensación por el agravio cometido contra mí, me has llenado de elogíos en tu libro Ensayo Político, la mayoría de ellos son excesivos y algunos bien cualificados ... Hablando francamente, hubiera apreciado más que me hicieras menos alabanzas y hubiese habido más precisión (en el análisis químico de las muestras minerales entregadas) $\gg^{17}$.

Hemos visto como el viaje de Humboldt al Nuevo Mundo le pone en contacto con uno de los primeros científicos que desarrolló una metodología rigurosa para el estudio de los minerales en la Nueva España. De su amistad derivan excursiones científicas y debates que aportarán parte del abundante material empleado para elaborar las magnas obras del naturalista prusiano. La obra del novohispano, menos conocida y no tan monumental en numero de páginas, es fundamental para el conocimiento moderno de los minerales y base para su descubrimiento de un nuevo elementos químico, no reconocido en su momento por un claro prejuicio xenófobo. Este incidente es revelador de un momento clave en la historia de la ciencia, se estaba pasando de un pensamiento científico de tipo enciclopedista (representado por Humboldt) a un planteamiento nuevo que opta por criterios

15. Los resultados son publicado en la revista Annales de Chimie et de physique, 1805, $\mathrm{n}^{\circ}$ 53, pp. 268-271. La referencia de este asunto procede de CASWELL (2003), pág. 40.

16. M. del Río confunde la nacionalidad de Collet-Descotills que era francés y no alemán.

17. Los tres fragmentos seleccionados pertenecen a la «Carta dirigida al Sr. Barón de Humboldt», publicada en Mercurio de España, 1919, I, pp. 169-176. La referencia procede de CASWELL (2003), pág. 38. He traducido el texto de la citada referencia. 
más especializados (representado por del Río). La Geografía juega aquí su papel aportando elementos metodológicos específicos que son utilizados por los dos investigadores, siempre dentro del contexto del naturalismo ilustrado. Si bien uno será admirado en su momento y por las generaciones venideras, el otro deberá esperar el paso del tiempo para que al menos se le reconozca una de sus grandes aportaciones (el descubrimiento de un nuevo elemento químico). 


\section{BIBLIOGRAFÍA GENERAL}

Puig-SAmper, M.; ReboK, S. (2002). «Un sabio en la meseta. El viaje de Alejandro de Humboldt a España en I799», Revista Internacional de Estudios Humboldtianos, III, 5, pp. 3-I8.

CAswell, L. R. (2003). «Andrés Manuel del Río, Alexander von Humboldt and the twicediscovered element», Bulletin of Historial Chemistry, Vol. 28-I, pp. 35-4I.

CAPEL, H. (I98I). Filosofía y ciencia en la Geografía contemporánea, Barcelona, Ed. Barcanova, 509 pp.

Fortes, J.; Adler, L. (I990). Becoming A Scientist In Mexico. The Challenge of Creating a Scientific Community in an Underdeveloped Country, Penn State University Press. 236 pp.

Frolova, M. (2002)- «La evolución de la geografía y del trabajo del geógrafo en Rusia». Scripta Nova, Revista Electrónica de Geografía y Ciencias Sociales, Universidad de Barcelona, vol. VI, no II9 (80), <http://www.ub.es/geocrit/sn/snII9-80.htm> [Consultado 26/04/20I8].

Martín Vaqueiro, N. (20I7). «Expedición de los hermanos Heuland a Chile y Perú», Espacio, tiempo y forma ,I66 - VI • Geografía Io, pág. I65-I77.

Uribe Salas, J. A. (2006). «Labor de Andrés Manuel del Río en México: profesor en el Real Seminario de Minería e innovador tecnológico en minas y ferrerías», Asclepio. Revista de Historia de la Medician y la Ciencia, Vol LVIII, 2, pp. 23I-26o.

Roca BAREA. M ${ }^{\mathrm{a}}$. E. (20I7). Imperiofobia y leyenda negra, Madrid, Siruela, $483 \mathrm{pp}$.

Obras de A. de Humboldt y A. M. del Río mencionadas en el texto:

ANDRÉS MANuel Del Río

(1795), Elementos de Orictognosia o del conocimiento de los fósiles, dispuestos, según los principios de A.G. Werner, para el Uso del Real Seminario de Minería de México, segunda parte: México, Imprenta de Don Mariano de Zúñiga y Ontiveros, XII - 200 pp.

(1835), Elementos de orictognosia o del conocimiento de los fósiles según el sistema de Bercelio, y según los principios de Abraham Gottlob Werner, con la sinonimia inglesa, alemana y francesa para el uso del Seminario Nacional de Minería de México, parte práctica, segunda edición: Filadelfia, Estados Unidos de América, Imprenta de Juan F. Hurtel, 683 pp.

(1985). Elementos de Orictognosia o del conocimiento de los fósiles, dispuestos, según los principios de A.G. Werner, para el Uso del Real Seminario de Minería de México, Madrid, Universidad Complutense, primera parte, I7I p.; segunda parte, 200 pp., (edición facsímil).

Alexander von Humboldt

(I805). «Introducción a la pasigrafía geológica», en del Río, A.M., Elementos de Orictognosia (...), pp. I60-I73.

(I827). Ensayo político sobre la Nueva España, Tomo II. Paris, Jules Renoud (traducción de Vicente Gómez Arnao). <http://cdigital.dgb.uanl.mx/la/Io800I2467_C/I0800I2468_ T2/I0800I2468_MA> [Consultado I8/04/2018].

(I997, ed. Original de I859). Del Orinoco al Amazonas. Viaje a las regiones equinocciales del Nuevo Continente, Barcelona, Timun Mas, 422 pp.

(2003, ed. Original de I876). Cuadros de la Naturaleza, Madrid, Los Libros de la Catarata (traducción al español de Bernardo Giner de Los Ríos). 
SERIE VI GEOGRAFÍA

REVISTA DE LA FACULTAD DE GEOGRAFÍA E HISTORIA
AÑO 2018

ISSN: $1130-2968$

E-ISSN 2340-146X
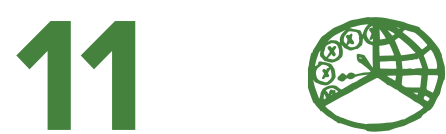

ESPACIO,

TIEMPO

Y FORMA
Reseñas · Book Review

\section{Artículos · Articles}

17 Juan Cruz Alberdi Collantes

Actuar desde la escala local: servicios de ensilado ante el abandono agrario · Acting

from the Local Scale: Silage Services against Ground Abandonment

4.7 María Teresa Álvarez Zumeta

Valoración de paisajes culturales y potencial de los recursos turísticos en un territorio. Estudio de casos: El municipio de Lezo

and Potential of the Tourism Resources of a Territory. Case Study: The Municipality of Lezo

\section{Aurelio Cebrián Abellán}

Necesarios reajustes de planificación en diseños turísticos funcionales: ejemplo de la Ruta Amanecista. Functional Tourist Designs and the Necessary Evolutionary

\section{Adjustments. The Example of the Amanecista Route}

Mario Corral Ribera; Concepción Fidalgo hijano \& Begoña Peco Factores ambientales en la distribución de la seca en la encina (Quercus ilex subsp. ballota) . Environmental Variables in the Distribution of la Seca Disease in the Holm Oak (Quercus Ilex Subsp. Ballota)

西

Análisis del efecto de variables ambientales en la estimación de la erosionabilidad (Factor K) - Analysis of the Effect of Environmental Variables on the

\section{Miguel A. Sánchez-Celada}

21 Evolución urbana de Ponce (Puerto Rico), según la Cartografía Histórica

24. José RAmón SÁnChEZ Holgado
La puesta en valor del patrimonio cultural de La Herradura: el hundimiento parcial de la flota del Mediterráneo de Felipe II. The Enhancement of the Cultural
Heritage of La Herradura: The Partial Sinking of Philip II's Fleet in the Mediterranean

María José Jiménez Meseguer \& Francisco José Morales Yago

El casco antiguo de Cartagena: transformaciones urbanísticas y patrimoniales

\section{O Fernández Portela} nic Diversification in a Traditional Wine-Growing Region: The Bases that Sustain ante la recuperación de su paisaje cultural · The Old Town of Cartagena: Urban and 